\title{
La apuesta por la interdisciplinariedad en los estudios de periodismo en la obra de Luis Núñez Ladevéze
}

\section{Commitment to Interdisciplinary in Journalism Studies in Luis Núñez Ladevéze's Thought}

Fernando López Pan. Universidad de Navarra (lopezpan@unav.es)

Resumen:

Los estudios de Periodismo como disciplina universitaria necesitan todavía una clara delimitación de su estatuto académico, que, entre otros aspectos, debe dar respuesta a su naturaleza, objetivos, metodología y ámbitos. En este debate, y para el caso de España, frente a una abundante producción manualística y una investigación madura, abundante y creciente, las aportaciones metadisciplinares son más bien escasas. Entre ellas, destacan las de Núñez-Ladeveze, cuyas investigaciones subrayan y ejemplifican la trascendencia de una metodología interdisciplinar. Esta nota sintetiza cómo entiende la Periodística, paso previo para un proyecto de más envergadura sobre la historia general de la disciplina, que exigirá una profundización en su obra.

Palabras clave:

Estudios de Periodismo; Periodística; Núñez Ladevéze; metadisciplinariedad; interdisciplinariedad.

Abstract:

Journalism Studies as a field of research is still awaiting a clear delineation of their academic status, which, among other things, must respond to their nature, objectives, methodology and scope. In this discussion and in the case of Spain, we find rather scarce metadisciplinary contributions almost 45 years after the entrance of the Journalism into the University, although there has been numerous production of textbooks, and a very abundant and growing research, A relevant metadisciplinary contribution is that of Núnez-Ladevéze, whose research demonstrates and exemplifies the importance of an interdisciplinary approach, This note synthesizes how he understands the discipline, a stage of a larger project on the general history of the discipline, which requires a necessary in deep analysis of his work.

Keywords:

Journalism Studies; Núñez Ladevéze; Interdisciplinarity; Metadisciplinarity. 
La historia de la Periodística en España es una tarea pendiente (López Pan, 2009a) -y esencial- que debería empezar con los autores y estudiosos del área que han abordado -explícita o implícitamente- cuestiones metadisciplinares: objetivos y campos, método y naturaleza de la disciplina. Hasta el momento se han abordado las aportaciones de Martínez Albertos (López Pan, 2009b) y Casasús (López Pan, 2010). En esta nota se perfilarán las de Núñez Ladevéze, a quien, junto con Gomis y los dos mencionados, se considera uno de los iniciadores de la disciplina en la universidad (Análisis, 2002). No se estudia aquí el conjunto de su obra con la hondura y profundidad analítica que merece ni sus aportaciones se sitúan en el contexto académico y temporal en el que las planteó. Esta nota se limita a sintetizar las líneas maestras -dispersas, y en alguno casos latentes- de cómo entiende Núñez Ladevéze la disciplina que ampara su amplia producción. Por tanto, se concibe como una aproximación a un trabajo de más envergadura en el que el análisis de su obra se entrecruza con la historia general de la disciplina y las aportaciones de otros autores, en cuya nómina, aparte de los ya citados, se incluyen Del Rey (1988), Chillón (1989 y 1999), Burguet (1997), Aguinaga (2000), Borrat (2002), Vidal (2002) y Casals (2004).

En lo que atañe a los estudios sobre Periodismo, Núñez Ladevéze debuta con Lenguaje y comunicación. Para una teoría de la Redacción Periodística (1977), una obra más bien teórica, en la que plantea como objeto de estudio un lenguaje funcional, intermediario entre "lenguajes especializados y el lenguaje común" y caracterizado por la concisión, la claridad y la rapidez (1977: 126). Precisamente, justificaba la disciplina porque "la elaboración de la información como `mensaje’ exige una especialización en 'redacción periodística', un intermediario especializado" (1977: 58). En esta obra primeriza se advierte, como propuesta disciplinar, una interdisciplinariedad -convergen la Teoría de la comunicación, la Lingüística o la Filosofía del lenguaje- que se convertirá en un rasgo identificador a partir de entonces.

Las cuestiones metadisciplinares se reducen al mínimo en El lenguaje de los media. Introducción a una teoría de la actividad periodística (1979), "un ensayo de síntesis": más un "tanteo conceptual y discursivo" que una "teoría exhaustiva y rigurosa” (1979: 11), en el que combina la indagación sobre las teorías que abordan los medios de "comunicación de masas" y la finalidad didáctica.

Núñez Ladevéze justifica esa presencia de lo metadisciplinar en ambos trabajos -nítida en el primero, y casi latente en el segundo- por la juventud de la teoría de la comunicación colectiva (a su juicio, todavía muy desorientada en aspectos conceptuales y metodológicos) y de las entonces recién creadas facultades de Ciencias de la Información, "en las que casi todo, desde el punto de vista científico o del didáctico, está aún por hacer”: ni había un corpus de conceptos ni una tradición para contrastar (1979: 12).

Tras doce años de reflexión y de práctica del periodismo, publica Manual para Periodismo (1991), una respuesta a la búsqueda del sentido de su propio quehacer universitario, o, mejor, al intento de explicar/se su propia identidad como académico del área. En ese libro ya no aparecen referencias a una disciplina, ni siquiera al preguntarse por la función de 
las facultades que enseñan periodismo, ni al diseñar para ellas un lugar docente e investigador cuya formación cumpla dos exigencias ineludibles:

1. Ser auténticamente académica.

2. Adiestrar a los estudiantes en el ejercicio de la profesión. Asunto al que volverá once años después en "Encuentro entre teoría y práctica del periodismo desde un enfoque interdisciplinario" (2002).

Entre el manual y el artículo hay una perfecta continuidad de planteamientos que facilita una exposición conjunta, temática -no cronológica- e integradora, donde el análisis y la síntesis han obligado a romper la estructura de la argumentación del propio autor, quien con frecuencia avanza en espiral. Por otro lado, en ambos textos, las cuestiones metadisciplinares aparecen implícitamente al cuestionarse la presencia del Periodismo en la universidad, y la naturaleza de una teoría vinculada a la práctica profesional. De ahí que los dos próximos epígrafes se centren en la respuesta a esas dos preguntas, pero siempre en el horizonte de una metadisciplinariedad que se sintetiza y evalúa parcialmente en el balance final.

\section{El periodismo en la universidad}

Sobre la presencia del Periodismo en la universidad existe, como es lógico, una abundante bibliografía, y las explicaciones de Núñez Ladevéze tienen mucho de compendio y síntesis. Ahora bien esa síntesis presenta una originalidad que apunta a las respuestas que buscamos sobre las cuestiones metadisciplinares; de ahí que sea imprescindible acompañarle en ese recorrido.

La relevancia social del Periodismo -explica- hizo que la universidad le prestara atención desde bien temprano, pero con el interés evidente de "investigar cómo influye el periodismo en la sociedad [más] que preocuparse por la formación de los periodistas, ya que pueden aprender ejercitándose en el oficio junto a otros más experimentados" (2002: 83). Dado que el Periodismo ayudaba a conocer la sociedad y sus cambios de rumbo (2002: 84), se impuso inicialmente una aproximación marcadamente sociológica, típica de la publicística alemana y de los estudios de opinión pública y comunicación de masas estadounidenses. Al respecto, hacía una llamada de atención porque, de seguirse esa perspectiva, el Periodismo en la universidad se desvincularía del ejercicio de la profesión, con el riesgo de caer en una teoría descarnada, con dos efectos: los estudiantes de esas disciplinas funcionarían al margen de la profesión y los periodistas se separarían de la Universidad, entre otras cosas porque su preparación se realizaría entonces en un entorno estrictamente profesional. Y lo considera una equivocación porque sostiene que sólo tiene sentido que la universidad acoja el Periodismo siempre que lo aborde no como tema, sino como actividad profesional (1991: 15), donde lo teórico y lo práctico se aúnen. 
Así, frente al modelo estadounidense -que se desdobla en facultades de comunicación interesadas en las cuestiones teóricas desde perspectivas más bien sociológicas; y escuelas de periodismo, centradas en las destrezas profesionales-, defiende la solución española de crear facultades de Ciencias de la Información de naturaleza bifronte que combinan lo teórico-académico con la formación práctica. De hecho, en los iniciales planes de estudio de esas facultades convivían asignaturas de diversa naturaleza: unas más teóricas, con marcado carácter sociológico y semiótico; otras más prácticas, principalmente las del área de la Redacción Periodística y el Periodismo Especializado; un tercer grupo de reconocida raigambre universitaria -Historia, Lengua y Literatura-, que daban al estudiante la imprescindible formación humanística; y otras dos -Derecho de la información y Empresa informativa-, que aportaban un conocimiento del contexto de la actividad periodística.

Esa combinación de materias teóricas y prácticas en una misma facultad creó un cauce institucional favorable para que no se impusieran de modo desproporcionado ni la perspectiva teórica, que daría pie al teoreticismo, ni la práctica, que se traduciría en lo que denomina practicismo. Ahora bien, ese marco institucional favorable -alertaba- no garantiza que no se caiga en una dualidad que separe ambos aspectos y sitúe "a unos en las zona del aprendizaje de un oficio y a otros en el ámbito de las ciencias sociales" (2002: 87). De hecho, piensa que en el paso de las escuelas a las facultades se había podido caer en el mencionado teoreticismo: la influencia excesiva de unas ciencias sociales que imponen "la subordinación de toda práctica a una previa explicación teórica” (2002: 87) habría empujado al error de separar la descripción del objeto y la práctica. Sin duda, error, pero no menos peligroso que el practicismo, que convertiría a las facultades en talleres y no daría a los estudiantes la necesaria formación integral.

Frente al teoreticismo distanciado de la práctica y al practicismo profesional, sugiere una vía de encuentro: la Redacción Periodística y el Periodismo Especializado, materias a las que interesa la actividad periodística; es decir, pretenden "saber qué hacen los periodistas cuando ejercen su oficio para poder enseñarlo a quienes tratan de aprenderlo" (2002: 89). A su juicio, cualquier respuesta exige describir los productos periodísticos, observar sus componentes, las reglas que se aplican para realizarlos (criterios de selección, titulación, redacción, etc.) y los nexos entre decisiones periodísticas y textos. Se trataría de explicar "qué hace el periodista al informar, al titular, al seleccionar, al evaluar la información, al opinar o al redactar" (2002: 89). Surgen así preguntas más profundas y radicales: ¿Existen reglas uniformes para la selección y la evaluación? Si existen habrá que buscarlas. ¿Los títulos responden a estructuras pragmáticas o textuales discernibles? ¿Qué relaciones hay entre la sintaxis y la estructura textual de títulos y textos? Las respuestas -señala- ayudarían a encontrar el gozne entre análisis, descripción y práctica del oficio.

Precisamente, estudiar esas reglas y esas estructuras pragmáticas (se mencionan a título de ejemplo) constituirían para Núñez Ladevéze el objeto de estudio de la Redacción Periodística y el Periodismo Especializado. Así, el profesor-investigador de esas materias debería esforzarse por desentrañar los elementos constitutivos del Periodismo, pero yendo más allá 
de una mera descripción del trabajo del periodista y de la acumulación de normas de procedimiento y consejos - "interesantes y útiles", desde luego- tan frecuente en los manuales al uso (1991: 26). Es decir, adentrándose en una teoría orientada a la práctica, y en una práctica imbricada con una teoría explicativa, tal y como se aborda en el siguiente epígrafe.

\section{La necesaria interdisciplinariedad de una teoría vinculada a la práctica}

Una teoría orientada a la práctica -sostiene- debería nacer “de las observaciones” y estar "enfocada a la aplicación” (1991: 15), y usar "los conceptos teóricos como instrumentos que llevan al nivel consciente las pautas a que responden los hábitos intuitivos e inconscientemente consolidados mediante el ejercicio práctico" (1991: 14). Para que la teoría no pierda pie, propone como método “enfocar disciplinas genéricas hacia el ámbito material específico del periodismo" (1991: 15). Y en concreto, plantea la integración -no la simple yuxtaposición- de la Lingüística, el Análisis de textos y la Sociología de la comunicación de masas (1991: 16) orientadas a un mismo objeto -el Periodismo-, y con un enfoque específico, que, al relacionar lengua y funciones sociales de los textos, permita tratar "unitariamente lo que materialmente se expresa como unidad" (1991: 16).

Con su Manual para Periodismo intenta mostrar que cabe esa teoría para la práctica, o esa dimensión teórico-práctica donde las "nociones sistematizadas":

1. "procedan de la materia empírica",

2. “den razón, en su dimensión abstracta, de los hechos concretos” y

3. "expliquen, elevando al plano de la reflexión consciente, los procedimientos y pautas que inconscientemente ejecutan los propios periodistas" (1991: 12).

Esa teoría explicativa del periodismo -que se enmarca en otra general de la acción humana- incluye la teoría del texto (1991: 25): al fin y al cabo, señala, los productos periodísticos son textos, con determinados rasgos formales y con funciones sociales a las que se adaptan. Y-añade-como sucede con todo texto, el periodístico depende del contexto de referencia: aquello a lo que se refiere el texto; y del contexto de interpretación: el acontecer del que la noticia es una unidad de información y un elemento del proceso del acontecer.

Por tanto -continúa-, por un lado, hay que examinar la noticia como texto que presenta "aspectos distintivos del lenguaje, el estilo y la redacción informativa y las pautas que los periodistas aplican para determinar la coherencia lineal y global del texto informativo" (1991: 25). Y, por otro, es imprescindible identificar los criterios de evaluación, identificación y determinación de las noticias. La textualidad de la noticia y la identificación de los criterios mencionados permiten "determinar reglas a posteriori relativas al estilo y construcción del texto informativo” (1991: 25). Mostrar cómo afronta Núñez Lade- 
véze esa tarea, obligaría a adentrarse con detalle en el manual, algo que excede el objetivo de este trabajo introductorio. Sin embargo, sí conviene sintetizar su idea sobre la naturaleza del Periodismo y cómo abordarla.

\subsection{Algunas notas sobre la naturaleza del Periodismo}

En el artículo de 2002, vuelve a plantearse qué define el periodismo, y retoma la idea de una actividad periodística mediadora y productora, que el periodista -añade- realiza a través de "un relato mediador" (2002: 89), que abre las puertas a la Teoría de la narración. Ahora bien, advierte que tanto esta como la tradicional estilística periodística son adyacentes porque "no penetran en la peculiaridad de lo propiamente periodístico y tienen un valor principalmente normativo" (2002: 91).

Por otro lado, señala que los relatos periodísticos no narran cualquier cosa sino asuntos de interés, por lo que considera imprescindible retroceder al plano contextual, en el que actúan unas reglas de selección tan importantes que los periodistas, en competencia con otros y al servicio de un público con capacidad de elección, pueden acertar o no con sus decisiones.

Esa dimensión contextual de la actividad periodística apuntaría a los aspectos sociológicos de la conducta profesional, asequibles a los métodos de la Sociología comprensiva, la Teoría intencional de la acción y la Pragmática (herencia de la sociología de la comunicación y la publicística). Pero esas disciplinas, a su juicio, todavía no permiten desentrañar algo más importante desde la perspectiva teórico-práctica: las relaciones entre las conductas y los productos periodísticos (2002: 90), simples textos insertados en un contexto y realizados a través del lenguaje. Pues bien, esas relaciones sólo pueden ser abordadas por una Teoría del texto y una Pragmática del lenguaje.

Sin embargo, afirmaba, la teoría del texto y la pragmática del lenguaje apenas se habían aplicado entonces a los estudios de los productos periodísticos. Quizá por esa razón se siente obligado a explicar en 2002 algunas cuestiones básicas de pragmática y su conexión con el periodismo. Habla así de dos problemas:

\section{a) En cuanto al periodista y el contenido del acto de informar.}

El informador se enfrenta con actos discursivos o actos de habla que -como la Pragmática ha demostrado-son "un modo de actuar sobre el mundo y no su mera representación" (2002: 92). Por eso -subraya-, el periodista ha de distinguir entre comprender el significado e interpretar la acción: se comprende un signo, pero se interpreta ese signo en función del contexto. Ciertamente, eso implica que el acto de informar es en sí mismo interpretativo, porque se refiere a una intención global no expresa (estratégica para quien la produce), y el informador ha de reflejar la literalidad y sus constituyentes comunicativos (intencionalidad no expresa). El periodista -añade- se ve abocado así a la difícil tarea de lograr la referencialidad al tiempo que debe interpretar la acción humana y su sentido. Y la relación entre ambos aspectos del acto 
de informar es "el nexo entre la teoría y la práctica, porque al analizarlo exhibimos también la regla que aplica para producirlo" (2002: 94).

\section{b) En cuanto al lector y los actos discursivos del periodista.}

El lector se encuentra con textos compuestos por el periodista que, a su vez, son actos discursivos, con su naturaleza bifronte: significado (del signo) y sentido (de la acción). En ambos casos, se requiere el análisis de textos y una alianza entre Lingüística y Sociología "no sólo para la interpretación de los enmascaramientos y las actitudes ideológicas encubiertas por la actividad informativa, sino también para entender cómo el periodismo interpreta el objeto de su información” (2002: 93). Por tanto, habla de un sentido informativo que recae "sobre una acción intencional de sentido no expreso que habrá que indagar. En el fondo, esto responde a que las acciones humanas se definen por su pretensión de producir sentido (2002: 94).

En este contexto, señala que el Periodismo produce realidad social y contribuye a modificarla. Por eso, por un lado, el estudio de los productos periodísticos puede entenderse también "como una aportación a cómo la actividad periodística contribuye a producir -no meramente reproducir- la realidad social en la que se integra” (2002: 93). Por otro, los supuestos fenomenológicos en los que se basa la sociología de la producción de la realidad entran así en contacto con los pragmáticos de la teoría de la acción” (2002: 95). Y ese es el punto de conexión de distintos enfoques interdisciplinares: si un enunciado es fruto de una actividad fabril y es una acción en el mundo, cabe enlazar pragmática y fenomenología, y completar la perspectiva con la teoría de la acción y del texto.

No es este el lugar para entrar con detenimiento en la argumentación de Núñez Ladevéze, como ya se indicó en la introducción de esta nota; pero sí parece obligado concluir con su definición de la actividad periodística: “Una acción de tipo poiético, consistente en producir objetos, cuyas específicas reglas productivas pueden estudiarse a través de un teoría del texto, pero en la que los aspectos pragmáticos son muchas veces inseparables de los poiéticos, por lo que es necesario entenderlos desde una teoría de la intencionalidad y de los actos de habla" (2002: 96).

\section{Balance y valoración: una trayectoria innovadora}

3.1. Las primeras obras de Núñez Ladevéze sobre Redacción Periodística (1977 y 1979) son un intento explícito de definir los contornos de la disciplina. En sus trabajos posteriores (1991a y b; 2002, 2004), la preocupación metadisciplinar sólo se mantendrá de modo latente y desde una perspectiva distinta: la de preguntarse por la formación universitaria de los periodistas y por la tarea específica del profesor universitario de Periodismo.

3.2. El compromiso de Núñez Ladevéze por encontrar el sentido a su profesión académica se concreta en una seria e intensa preocupación por saber cómo afrontar una tarea docente e investigadora con la altura intelectual y teórica 
propia del ámbito universitario, que proporcione el adiestramiento práctico -precisamente el interés dominante en la tradición- y que proponga explicaciones, razonamientos y reflexiones útiles a los periodistas (es decir, que también a ellos les ayude descubrir el sentido de lo que hacen). Esas coordenadas le ubican intelectualmente en el contexto universitario (en su doble faceta docente e investigadora) y en el de la industria del Periodismo y la comunicación.

3.3. El profesor universitario de periodismo ubicado en la tradicional Redacción Periodística -donde encajarían de modo armónico las exigencias teóricas y las prácticas, evitando que estás se redujeran a un simple repertorio de consejos- convive con otros profesores universitarios de las facultades de periodismo que enseñan conocimientos complementarios (literatura, historia...), de contexto (jurídico y empresarial) y teóricos duros (teoría de la comunicación o de la información, etc.).

3.4. En la obra madura de Núñez Ladevéze, hay una clara despreocupación por acotar una disciplina. Apunta a la investigación en sí, quizá por eso evite las cuestiones terminológicas -que además, pueden acabar en disputas sobre asuntos secundarios- y ni siquiera discuta la existencia de una disciplina -algo obvio para él- ni su estatuto científico. También es posible que prefiera fijarse objetivos y testar métodos antes de afianzar mapas disciplinares.

3.5. Ahora bien, de sus planteamientos se puede deducir que hay un objeto, una naturaleza y una metodología para una disciplina autónoma (que no independiente). A saber:

3.5.1. Objeto. El Periodismo como actividad en sí misma, y no como tema de estudio de otras disciplinas. Plantea una articulación de teoría y práctica que no se limite a las cuestiones expresivas; y amplíe su ámbito de intereses a los "aspectos que son propios, inherentes a la actividad informativa en sí misma, al modo de realizarse para obtener información y a las técnicas de elaboración para que respondan al interés del público” (2002: 88). En la medida en la que empuja sus fronteras más allá de lo estrictamente redaccional o estilístico, prefiere no recurrir al tradicional nombre de Redacción Periodística; aunque no plantea otro alternativo porque le parece "inadecuado, pues la perspectiva adoptada era más comprensiva. La redacción pertenece a la estilística práctica, a una aplicación normativa de la gramática (pero no de la lingüística, ni de la semiótica... [y] a mi entender la Redacción Periodística no puede abarcar una teoría de la noticia, porque eso no es redacción, sino explicitación de reglas de comportamientos profesionales, rutinas o prácticas, como muy bien se ve en el libro de G. Tuchman (2014)”.

3.5.2. Naturaleza. Teórica, pero volcada en la práctica y con el objetivo de enriquecerla, desvelando a los periodistas lo que subyace en sus conductas y decisiones. 
3.5.3. Metodología. Una interdisciplinariedad integradora que enfoca hacia el periodismo unas disciplinas que ayudan a comprenderlo explicativa y analíticamente. En concreto, menciona la Teoría del texto y la Pragmática (aspecto de la Lingüística), la Sociología, la Teoría de la narración y la Teoría de la acción. "El enfoque interdisciplinario y el encuentro de las disciplinas es, pues, indispensable tanto para describir el objeto y sus productos como para mostrar las reglas productivas del texto y de su inserción social" (2002: 96). La consistencia y el peso específico de esa disciplina en el ámbito universitario -concluye- dependerán de que sepa allegar los recursos de esas otras disciplinas. La interdisciplinariedad integradora queda suficientemente demostrada en su caso. Por ejemplo:

3.5.3.1. La Lingüística. En sus investigaciones se van alternando estudios específicos de distintas áreas de esa disciplina con otros sobre Periodismo.

A modo de ejemplo, entre sus aportaciones cabría mencionar estas:

- Servirse de la Pragmática, y de la identificación de los tres niveles del acto discursivo (locutivo, ilocutivo y perlocutivo) para abordar el Periodismo como actividad perlocutiva.

- Aplicar las distinciones acerca de la coherencia al texto informativo, que define y caracteriza así con más detalle.

- Desarrollar la idea del periodista como intérprete del decir de otros, del macroacto de habla (por ejemplo, es con el que se titula con frecuencia una noticia discursiva).

- Señalar la peculiaridad del párrafo de entrada de las noticias: aunque sus consideraciones relativas al lead no difieren de la doctrina clásica, añade explicaciones que se asientan en conceptos tomados de la lingüística del texto, da una mayor solidez teórica a las recomendaciones frecuentes en los manuales, simple trasunto de las prácticas profesionales, y muestra mejor los mecanismos de construcción de esos párrafos.

- Proponer clasificaciones de los párrafos de entrada (también de los titulares) y ofrecer explicaciones muy clarificadoras acerca de la entrada como una macroestructura del cuerpo de la información, y el titular como una macroestructura del párrafo de entrada o la noción tan útil de 'contexto dentro del texto’ (1991a: 251-255).

3.5.3.2. También la perspectiva filosófica aparece en sus trabajos, por ejemplo, al abordar los géneros periodísticos, singularmente, la distinción -clave en las tipologías al uso- entre hechos y opiniones (2004b); o al definir el concepto de opinión, aparentemente sencillo, pero que "oculta complicaciones, [ya que] no es un asunto meramente periodístico, sino estrictamente filosófico” (2007: 15). 
3.6. Entre las ausencias que, hasta cierto punto, oscurecen sus planteamientos, señalaré tres:

3.6.1. Aunque los ámbitos que propone superan los tradicionales, parece mantenerse siempre en los contornos de un Periodismo escrito (en ningún momento aborda aspectos relacionados específicamente con el televisivo, el radiofónico y el digital), y tampoco da entrada a otros aspectos de los estudios de Periodismo, como, por citar dos ejemplos, la Historia del Periodismo y el Diseño.

3.6.2. Aparecen nociones y disciplinas que necesitarían ser mejor perfiladas. Ciertamente, cabe dar por supuesto que se conocen, pero ayudaría que las afinara de un modo explícito por dos razones. Una accidental y estratégica: no desorientar a los estudiosos que se acerquen a su obra. Al fin y al cabo, ya que parte de su originalidad dentro del área de conocimiento se debe a esa metadisciplinariedad, parece conveniente entrar en esos detalles que, en otras circunstancias, se darían por supuesto. Es decir, si la comunidad investigadora desconoce el terreno del que brotan horizontes investigadores, sería oportuno desarrollar sus fundamentos. Pero hay otra razón sustancial: los contornos de esas disciplinas, incluso entre los expertos, son difusos y se solapan entre sí. Por eso, convendría aclarar cómo entiende cada una.

3.6.3. En esta línea, no aparece de modo nítido el engranaje entre algunas disciplinas y sus principios de aplicación a la actividad periodística. Tampoco -aunque alude a ello en algunos pasajes- el entrelazamiento entre las distintas disciplinas: es decir, el modo operativo de esa integración.

3.7. Núñez Ladevéze es, sin duda, una voz innovadora a lo largo de su trayectoria académica, también, aunque se presenten implícitamente en sus diferentes investigaciones, en cuanto a propuestas metadisciplinares, que son las que interesan en estas páginas. En una valoración de conjunto, cabe destacar que ha buscado con originalidad una ubicación para el profesor de periodismo en el contexto universitario, sugiriendo qué tipo de investigación hacer y cómo articularla e integrarla en la docencia.

\section{Referencias bibliográficas}

Aguinaga, E. (2000): “Nuevo concepto de Redacción Periodística”, Estudios del Mensaje Periodístico, n. 6.

Borrat, H. (2002): “Paradigmas alternativos y redefiniciones conceptuales en comunicación periodística”, Anàlisi, n. 28, pp. 55-77.

Burguet, F. (1997): Construir les notícies. Una teoria de la redacció periodística. Barcelona: Dèria Editors.

Casals, M. J. (2004): “La enseñanza del Periodismo: Universidad, conceptos, modelos y Redacción Periodística”, en Casals, M. J. (Coord.): Mensajes periodísticos y sociedad del conocimiento. Libro homenaje al profesor José Luis Martínez Albertos. Madrid: Fragua, pp. 465-485. 
Del Rey, J. (1988): "Estatuto epistemológico de la Redacción Periodística”, Revista de Ciencias de la Información, n. 5 (Monográfico: “Los mensajes de la comunicación periodística”), pp. 113-122.

Chillón, Ll. A. (1999): Literatura y periodismo. Una tradición de relaciones promiscuas. Barcelona: Universitat Autònoma de Barcelona.

- (1989): "Què pot manllevar el Periodisme a la Literatura? Propostes per a la fonamentació del comparatisme periodístico-literari”, Periodística, n. 1, pp. 113-128.

Gómis, L., Martínez Albertos, J. L., Núñez Ladevéze, L. y Casasús, J. M. (2002): “Encuesta: ¿vive la comunicación periodística un cambio de paradigma?", Anàlisi, n. 28, pp. 157-185.

Jones, D. E. (1998): “Investigación sobre comunicación en España: evolución y perspectivas”, en ZER, n. 5, pp. 13-51.

López Pan, F. (2009a): “La Redacción Periodística como disciplina. Una historia pendiente”, Textual \& Visual Media, n. 2, pp. 201-214.

- (2009b): "La centralidad de las formas expresivas y los géneros periodísticos. Martínez Albertos y el estatuto de la Redacción Periodística", Comunicación y Pluralismo, n. 8, pp. 9-28.

- (2010): “La Periodística y sus partes. La propuesta de Josep Maria Casasús”, Sphera Publica, n. 10, pp. 237-258.

Núñez Ladevéze, L. (1977): Lenguaje y comunicación: para una teoría de la redacción periodística. Madrid: Pirámide.

- (1979): El lenguaje de los "media": Introducción a una teoría de la actividad periodística. Madrid: Pirámide.

- (1991a): La construcción del texto. Madrid: EUDEMA.

- (1991b): Manual para Periodismo. Veinte lecciones sobre el contexto, el lenguaje y el texto de la información. Barcelona: Ariel.

- (1991c): “Estilo, texto y contexto en periodismo”, en Casasús, J. M. y Núñez Ladevéze, L.: Estilo y géneros periodísticos. Barcelona: Ariel, pp. 99-181.

- (1995): Introducción al Periodismo escrito. Barcelona: Ariel.

- (2002): “Encuentro entre teoría y práctica del periodismo desde un enfoque interdisciplinario”, Anàlisi, n. 28, pp. 7996.

- (2004a): “El periodismo desde un enfoque interdisciplinar”, en Cantavella, J. y Serrano, J.F. (coords.): Redacción para periodistas: informar e interpretar. Barcelona: Ariel, pp. 17-50.

- (2004b): “Los hechos no son libres ni las opiniones sagradas”, Telos, n. 58. Enero-marzo, pp. 49-62.

- (2007): “Los géneros periodísticos y la opinión", en Cantavella, J. y Serrano, J. F. (coords.): Redacción para periodistas: Opinar y argumentar. Madrid: Universitas, pp. 15-54. 
Peters, J. D. (1986): “Institutional Sources of Intellectual Poverty in Communication Research”, Communication Research, n. 13.4, pp. 527-559.

Vidal, D. (2002): “La transformació de la teoria del periodisme: una crisi de paradigma?”, Anàlisi, n. 28, pp. 21-54. 